\title{
Tetraanionic arachno-Carboranyl Ligand Imparts Strong Axiality to Terbium(III) Single-Molecule Magnets
}

\author{
Peng-Bo Jin, ${ }^{a}$ Ke-Xin Yu, ${ }^{a}$ Qian-Cheng Luo, ${ }^{a}$ Ye-Ye, Liu, ${ }^{a}$ Yuan-Qi Zhai ${ }^{a}$ and and Yan-Zhen Zheng ${ }^{*, a}$
}

[a] P-B. Jin, K-X. Yu, Q.-C. Luo, Y.-Y. Liu, Y-Q. Zhai, and Prof. Dr. Y.-Z. Zheng

Frontier Institute of Science and Technology (FIST), State Key Laboratory of Mechanical Behavior, MOE Key Laboratory for Nonequilibrium Synthesis and Modulation of Condensed Mater, Xi'an Key Laboratory of Sustainable Energy and Materials Chemistry, School of Chemistry and School of Physics, Xi'an Jiaotong University, 99 Yanxiang Road,

Xi'an, Shaanxi 710054, P. R. China.

Fax: (+) 86-29-83395909

Email: zheng.yanzhen@xjtu.edu.cn

http://gr.xitu.edu.cn/web/zheng.yanzhen/home

\begin{abstract}
A family of fully sandwiched arachno-lanthanacarborane complexes formulated as $\left\{\eta^{6}-\left[\mu-1,2-\left[0-C_{6} H_{4}\left(\mathrm{CH}_{2}\right)_{2}\right]-1,2-\right.\right.$ $\left.\left.\mathrm{C}_{2} \mathrm{~B}_{10} \mathrm{H}_{10}\right]_{2} L n\right\}\left\{\mathrm{Li}_{5}(\mathrm{THF})_{10}\right\}$ (Ln $\left.=\mathrm{Tb}, \mathrm{Dy}, \mathrm{Ho}, \mathrm{Er}, \mathrm{Y}\right)$ is successfully synthesized, where the "carbons-adjacent" carboranyl ligand (arachno- $\mathrm{C}_{2} \mathrm{~B}_{10} \mathrm{H}_{10^{4-}}$ ) bears four negative charges and coordinates to the central lanthanide ions using the hexagonal $\eta^{6}-C_{2} B_{4}$ face. Thus, the central lanthanide cations are pseudo-twelve-coordinate and have an approximate local $D_{6 h}$ symmetry or hexagonal-prismatic geometry. As the crystal field effect imparted by this geometry is still unknown, we thoroughly investigated the magnetic properties of this series of complexes and found the crystal field imposed by this ligand causes a relation of $\mathrm{Tb}>\mathrm{Dy}>\mathrm{Ho}>\mathrm{Er}$ for the energy gaps between the ground and the first excited states, which is of striking resemblance to the ferrocenophane and phthalocyanine ligands despite that the latter two ligands give disparate local coordination geometries. Moreover, the effective energy barrier to magnetization reversal of 445(10) $K$, observable hysteresis loop up to $4 K$ and the relaxation time of the yttrium diluted sample reaching 193(17) seconds at $2 \mathrm{~K}$ under an optimized field for the Tb analogue of this family of arachno-lanthanacarborane complexes, render a new benchmark for $\mathrm{Tb}^{3+}$ based single-molecule magnets.
\end{abstract}

A molecule that can store bytes information is appealing due to the facile assembly of such large number of entities from solution to crystal solids and vice versa. Thus, such a molecule is termed as single-molecule magnet (SMM), which has the full function of a magnetic material and can be used to store massive information within a small volume. ${ }^{[1]}$ However, to make the working temperature of these molecules as high as possible the local environment of the metal ions should be dedicatedly engineered by means of coordination chemistry. ${ }^{[2]}$ Heavy lanthanide cations of $\mathrm{Tb}^{3+}, \mathrm{Dy}^{3+}, \mathrm{Ho}^{3+}$ and $\mathrm{Er}^{3+}$ are mostly concentrated for building high-performance SMMs owing to the large magnetic anisotropy originated from large unquenched orbital angular momentum and strong spin-orbit coupling effect. ${ }^{[3]}$ Once the effective energy barrier $\left(U_{\text {eff }}\right)$ arising from magnetic anisotropy is large enough the magnetization reversal is slowed and finally blocked. This temperature is termed as blocking temperature $\left(T_{\mathrm{B}}\right)$ for SMMs. Technically, $T_{\mathrm{B}}$ can be measured by the temperature with maximum zero-field-cooling (ZFC) susceptibilities $\left(T_{\mathrm{B}}^{\mathrm{ZFC}}\right)$; the temperature where the relaxation time is $100 \mathrm{~S}\left(T_{\mathrm{B}}{ }^{100 \mathrm{~s}}\right)$ and the temperature with an opened magnetic hysteresis loop $\left(T_{\mathrm{B}}{ }^{\mathrm{H}}\right)$.
Historically, the first lanthanide SMM - $\left[\mathrm{TbPc}_{2}\right]^{-}(\mathrm{Pc}=$ dianion of phthalocyanine) - was reported by Ishikawa et. al in 2003. Here, the axial $\mathrm{Pc}^{2-}$ ligands display a square antiprismatic geometry to central $\mathrm{Tb}^{3+}$, resulting a well split and stabilized magnetic ground state with $U_{\text {eff }}=328 \mathrm{~K}^{\left[{ }^{[4]}\right.}$ In 2011 Gao et. al reported the first organometallic SMM - $\left[\left(\mathrm{Cp}^{*}\right) \operatorname{Er}(\mathrm{COT})\right](\mathrm{Cp}=$ cyclopentadienyl and COT = cyclooctatetraene ) - with $U_{\text {eff }}$ of $323 \mathrm{~K}^{[5]}$. From then on, $\mathrm{Ln}^{3+} \mathrm{SMMs}$ with $\eta^{\mathrm{n}}$-bound aromatic ligands of $\left[\mathrm{C}_{4}\right]^{2-},{ }^{[6]}\left[\mathrm{C}_{5}\right]^{-,{ }^{, 7-10]}}\left[\mathrm{C}_{4} \mathrm{P}\right]^{2-},{ }^{[11]}\left[\mathrm{C}_{8}\right]^{2-},{ }^{, 12]}$ and $\left[\mathrm{C}_{9}\right]^{-[13]}$ etc. were intensively investigated, resulting in record $U_{\text {eff }}$ of $2332 \mathrm{~K}$ and $T_{\mathrm{B}}{ }^{100 \mathrm{~s}}$ of $72 \mathrm{~K}$ in mixed-valence dinuclear complex $\left(\mathrm{Cp} \mathrm{ir}^{\mathrm{Pr} 5}\right)_{2} \mathrm{Dy}_{2} \mathrm{l}_{3} .{ }^{[\mathrm{cc}]}$ Our group also exploited a new organometallic SMMs with the dicarbollide dianion (Scheme 1a, left), which can generate strong ligand field to $\mathrm{Dy}^{3+}$ as well as Cp does. ${ }^{[14]}$

However, so far most of the high-performance SMMs are based on Kramers ions with half-integer spins such as $\mathrm{Dy}^{3+}$ and $\mathrm{Er}^{3+}$, which have the ground terms of ${ }^{6} \mathrm{H}_{15 / 2}$ and ${ }^{4} I_{15 / 2}$, respectively. For non-Kramers ion such as $\mathrm{Tb}^{3+}$ with integer spin $\left({ }^{7} F_{6}\right)$, the $\pm m_{J}$ degeneracy is not guaranteed and the inherent energy difference (or tunnel splitting, $\Delta_{\text {tun }}$ ) between two low lying states $\left(\left|m_{>}\right\rangle\right.$and $\left.\left|m_{j}\right\rangle\right)$ accelerates the quantum tunnelling of the magnetization (QTM) process, which makes faster magnetic relaxation. ${ }^{[15]}$ In this case, the ligands charge distribution should be guided with symmetry strategy to eliminate all transverse crystal field (CF) parameters and hence suppress the QTM by selecting the proper local symmetries such as $C_{n}(n>7$ including $\left.C_{\infty}\right), C_{5 h} / D_{5 h}, S_{8} / D_{4 \mathrm{~d}}$, and $S_{12} / D_{6 \mathrm{~d}} .^{[16-22]}$

The $D_{4 \mathrm{~d}}$ symmetry has showed great advantage in building $\mathrm{Tb}^{3+}$ based SMMs since the double-decker [ $\left.\mathrm{TbPc}_{2}\right]^{-}$ reported. ${ }^{[4],[23]}$ In this family, the heteroleptic bisphthalocyanine complex $\left[\mathrm{Tb}(\mathrm{Pc})\left(\mathrm{Pc}^{\prime}\right)\right]$ achieves a record effective magnetization energy barrier $U_{\text {eff }}$ of $932 \mathrm{~K}$ with optimized square-antiprism coordination geometry of the central $\mathrm{Tb}^{3+}$ ion. ${ }^{[24]}$ In addition to this coordination geometry, the ferrocenophane based $\left[\mathrm{TbFc}_{3}(\mathrm{THF})_{2} \mathrm{Li}_{2}\right]^{-}$complex with local trigonal prismatic geometry and quasi- $D_{3 \mathrm{~h}}$ symmetry occupies the second best performed $\mathrm{Tb}^{3+}$ SMMs. In addition to the phthalocyanine and ferrocenophane other ligand systems for reported $\mathrm{Tb}^{3+}$ SMMs can hardly achieve $U_{\text {eff }}$ larger than $100 \mathrm{~K}$ (Table 1) and most of them show slow magnetic behavior at relatively low temperatures. ${ }^{[27-33]}$ In particular for the $\mathrm{Cp}$ family the replacement of $\mathrm{Dy}^{3+}$ by $\mathrm{Tb}^{3+}$ makes the performance much deteriorated. ${ }^{[25],[26]}$ As such, the $T_{\mathrm{B}}{ }^{100 \mathrm{~S}}$ and $T_{\mathrm{B}}{ }^{\mathrm{ZFC}}$ have never been observed for reported $\mathrm{Tb}^{3+}$ based SMMs. 
Table 1. Reported mononuclear $\mathrm{Tb}^{3+}$ SMMs according to sequence of $U_{\text {eff. }}$

\begin{tabular}{lccc}
\hline $\mathrm{Tb}^{3+} \mathrm{SMMs}$ & $\begin{array}{c}U_{\text {eff }}(\mathrm{K}) \\
H_{\mathrm{dc}}=0\end{array}$ & $\begin{array}{c}T_{\mathrm{B}}{ }^{\mathrm{H}} \\
(\mathrm{K})\end{array}$ & Ref. \\
\hline$\left[\mathrm{Tb}(\mathrm{Pc})\left(\mathrm{Pc}^{\prime}\right)\right]$ & 932 & $/$ & 24 \\
$\mathbf{2 T b}$ & $445(10)$ & 4 & This work \\
{$\left[\mathrm{TbFc}_{3}(\mathrm{THF})_{2} \mathrm{Li}_{2}\right]^{-}$} & 393 & 2 & 26 \\
{$\left[\mathrm{TbPc}_{2}\right]^{-}$} & 328 & $/$ & 23 \\
{$\left[\mathrm{Cp}{ }_{2} \mathrm{~Tb}\left(\mathrm{BPh}_{4}\right)\right]$} & $/$ & 1.8 & 25 \\
{$\left[\mathrm{~Tb}\left(\mathrm{Cp}{ }^{\mathrm{ttt}}\right)_{2}\right]^{+}$} & 9.7 & $/$ & 35 \\
$\mathrm{~Tb}(\mathrm{picNN})_{3}\left(\mathrm{H}_{2} \mathrm{O}\right)_{6}$ & $22.8(5)$ & $/$ & 29 \\
{$\left[\mathrm{~Tb}(\mathrm{hfac})_{3}(\mathrm{NIT}-\right.$} & 8 & $/$ & 33 \\
{$\left[\mathrm{~Tb}(\mathrm{hfac})_{3}(\mathrm{NITPhOEt})_{2}\right]$} & 29.3 & $/$ & 27 \\
\hline
\end{tabular}

From the above examples we can see the crystal field splitting for the $\mathrm{Tb}^{3+}$ ion remains tricky compared to the Kramers ions such as $\mathrm{Dy}^{3+}$ and $\mathrm{Er}^{3+}$. When coordinating to the ring-like organometallic ligands small $\left[\mathrm{C}_{4}\right]^{2-}$ and $\left[\mathrm{C}_{5}\right]^{-}$are able to give strong axial crystal fields to $\mathrm{Dy}^{3+},{ }^{7-10]}$ while larger $\left[\mathrm{C}_{8}\right]^{2-}$ and $\left[\mathrm{C}_{9}\right]^{-}$ are more likely to obtain high performance $\mathrm{Er}^{3+}$ SMMs. $^{[12 a][13]}$ However, neither sizes of the rings are fitting to the $\mathrm{Tb}^{3+}$ ion in order to enhance the crystal field splitting of the ground and first excited states. ${ }^{[34],[35]}$ Thus, the exploration of crystal field splitting under the $\left[\mathrm{C}_{6}\right]^{\mathrm{x}-}$ and $\left[\mathrm{C}_{7}\right]^{\mathrm{y}-}$ rings is significant. For $\left[\mathrm{C}_{6}\right]^{\mathrm{x}-}$, the benzene ring is the handiest to explore, yet such a ligand always shows a variety of reducing species, such as $\left[\mathrm{C}_{6} \mathrm{H}_{6}\right],\left[\mathrm{C}_{6} \mathrm{H}_{6}\right]^{-}$ and $\left[\mathrm{C}_{6} \mathrm{H}_{6}\right]^{2-}$, which impose huge synthetic challenge. So far only gas phase complexes of low valent oxidation state for several lanthanides are known, ${ }^{[36],[37]}$ which are too sensitive to study the magnetic properties. Therefore, the crystal field effect imparted from the six member ringed ligand to the lanthanide ions remains unknown.

Herein, we develop a new hexadentate organometallic ligand, the novel arachno-carboranyl tetraanion (arachno- $\mathrm{R}_{2}-\mathrm{C}_{2} \mathrm{~B}_{10} \mathrm{H}_{10}{ }^{4-}$ ), which derives from the parental o-carborane molecule but consisting of both an open $\eta^{6}-\mathrm{C}_{2} \mathrm{~B}_{4}$ face and an open $\eta^{5}-\mathrm{C}_{2} \mathrm{~B}_{3}$ face, for coordinating to the lanthanide (Scheme 1a). ${ }^{[38]}$ Obviously, the frontier orbitals of $\left[\mathrm{C}_{2} \mathrm{~B}_{4}\right]$ hexagonal face is towards tilting to apices as the nido- $\mathrm{R}_{2}-\mathrm{C}_{2} \mathrm{~B}_{9} \mathrm{H}_{9}{ }^{2-}$ species does, indicating a major coordinating site. ${ }^{[39,40]}$
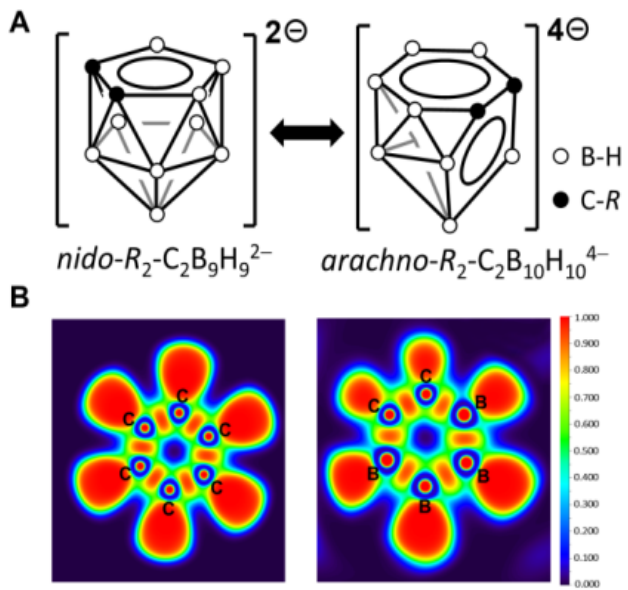

Scheme 1 The schematic diagram of the carboranyl ligands. (A) The comparison of the nido- $\mathrm{C}_{2} \mathrm{~B}_{9} \mathrm{H}_{11}{ }^{2-}$ and arachno- $\mathrm{R}_{2}-\mathrm{C}_{2} \mathrm{~B}_{10} \mathrm{H}_{10}{ }^{4-}$ ligands. (B) ELF coloring maps of benzene (left) and arachno- $\mathrm{R}_{2}-\mathrm{C}_{2} \mathrm{~B}_{10} \mathrm{H}_{10}{ }^{4-}$ (right). (The color from blue to red corresponds to ELF value varying from 0.0 to 1.0.).
Moreover, the electron localization function (ELF) analysis of the $\left[\mathrm{C}_{2} \mathrm{~B}_{4}\right]$ face via the Multiwfn program ${ }^{[41]}$ shows almost identical electron distribution image as benzene (Scheme 1b), suggesting an analogous aromaticity, but with four additional delocalized electrons. Such a unique feature of this ligand brings strong crystal field effect to the central lanthanide ions, which in turn dominates the magnetic property of this series of complexes (vide infra).

As shown in Scheme S1, fully sandwiched lanthanacarborane complexes, $\quad$ namely $\quad\left\{\eta^{6}-\left[\mu-1,2-\left[0-\mathrm{C}_{6} \mathrm{H}_{4}\left(\mathrm{CH}_{2}\right)_{2}\right]-1,2-\right.\right.$ $\left.\left.\mathrm{C}_{2} \mathrm{~B}_{10} \mathrm{H}_{10}\right]_{2} \mathrm{Ln}\right\}\left\{\mathrm{Li}_{5}(\mathrm{THF})_{10}\right\}$ (Ln = Tb, 2Tb; Dy, 2Dy; Ho, 2Ho; Er, 2Er; Y, 2Y), were synthesized using the metathesis reaction between anhydrous $\mathrm{LnCl}_{3}$ and the lithium salt of arachnocarborane, namely $\quad\left[\left\{\mu-1,2-\left[0-\mathrm{C}_{6} \mathrm{H}_{4}\left(\mathrm{CH}_{2}\right)_{2}\right]-1,2-\right.\right.$ $\left.\mathrm{C}_{2} \mathrm{~B}_{10} \mathrm{H}_{10} \mathrm{Li}_{4}(\mathrm{THF})_{6}\right]_{2}$ (1Li). The yttrium diluted samples of 2Dy@2Y and 2Tb@2Y were also prepared in a similar way (for synthetic detail, see Supporting Information).

A

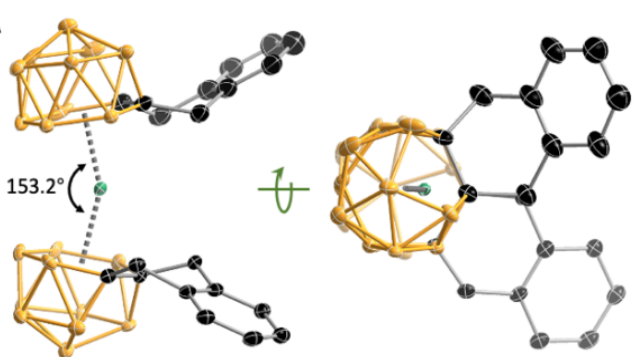

B

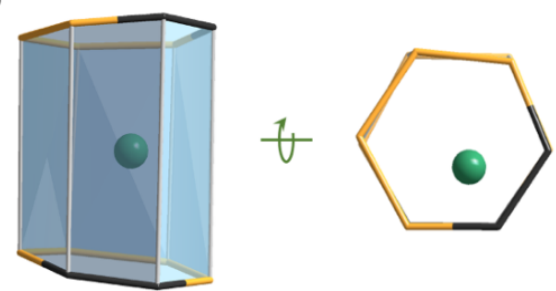

Figure 1 The crystallographic structure of 2Tb. (A) Molecular structure of the $\left\{\eta^{6}-\left[\mu-1,2-\left[o-\mathrm{C}_{6} \mathrm{H}_{4}\left(\mathrm{CH}_{2}\right)_{2}\right]-1,2-\mathrm{C}_{2} \mathrm{~B}_{10} \mathrm{H}_{10}\right]_{2} \mathrm{~Tb}\right\}^{5-}$ (thermal ellipsoids drawn at the $30 \%$ probability level and all the hydrogen atoms are omitted). Color codes: olive green, $\mathrm{Tb}^{3+}$; orange, $\mathrm{B}$; black, $\mathrm{C}$; and the same as follows. (B) Simplified molecular structure of $\left\{\eta^{6}-[\mu-1,2-[0-\right.$ $\left.\left.\left.\mathrm{C}_{6} \mathrm{H}_{4}\left(\mathrm{CH}_{2}\right)_{2}\right]-1,2-\mathrm{C}_{2} \mathrm{~B}_{10} \mathrm{H}_{10}\right]_{2} \mathrm{~Tb}\right\}^{5-}$ with distorted hexagonal-prismatic geometry.

The five complexes all crystallized in the chiral space group $P 2$. As they are isostructural, we only discuss the $\mathrm{Tb}^{3+}$. analogue as a representative. The anionic moiety of $2 \mathrm{~Tb}$, namely $\left\{\eta^{6}-\left[\mu-1,2-\left[0-\mathrm{C}_{6} \mathrm{H}_{4}\left(\mathrm{CH}_{2}\right)_{2}\right]-1,2-\mathrm{C}_{2} \mathrm{~B}_{10} \mathrm{H}_{10}\right]_{2} \mathrm{~Tb}\right\}^{5-}$, exhibits a full-sandwich structure where the central $\mathrm{Tb}^{3+}$ ion is sitting in the center of two $\mathrm{C}_{2} \mathrm{~B}_{4}$ hexagonal faces with the Centroid $\cdots$ Tb $\cdots$ Centroid angle of $153.2^{\circ}$ and short $\mathrm{Tb} \cdots$ Centroid distances of 2.038(2) - 2.039(2) $\AA$ (Figure $1 \mathrm{~A})$. The $\mathrm{Tb} \cdots \mathrm{B} / \mathrm{C}$ distances to the $\eta^{6}-\mathrm{C}_{2} \mathrm{~B}_{4}$ face range from $2.544(3) \AA$ to $2.796(2)$ $\AA$. Thus, the central $\mathrm{Tb}^{3+}$ ion is pseudo-twelve-coordinate and possesses a distorted hexagonal-prismatic geometry. Such a geometry imparts a pseudo- $D_{6 \mathrm{~h}}$ local symmetry to the central lanthanides (Figure 1B). The bulky and rigid groups of $o$-xylylene are staggered with an angle of with almost a linear inclination of $58.6^{\circ}$. This is obviously the origin of chirality of the complex arising from all achiral components including ligands, metal ions 
and other solvent molecules. The counter cations are comprising of five solvated lithium cations $\left\{\mathrm{Li}(\mathrm{THF})_{x}\right\}^{+}$attaching to the carboranyl cages by means of triple or quadruple $\mathrm{Li} \cdots \mathrm{H}-\mathrm{B}$ interactions. The absence of $\mathrm{Li} \cdots \eta^{5}-\mathrm{C}_{2} \mathrm{~B}_{3}$ bonding (indicated by the open bonds) interactions is much different from that of the pristine lithium salt $\left[\left\{\mu-1,2-\left[0-\mathrm{C}_{6} \mathrm{H}_{4}\left(\mathrm{CH}_{2}\right)_{2}\right]-1,2-\right.\right.$ $\left.\left.\mathrm{C}_{2} \mathrm{~B}_{10} \mathrm{H}_{10}\right\} \mathrm{Li}_{4}(\mathrm{THF})_{6}\right]_{2}$.

It is worth noting that each crystal of $2 \mathrm{~Tb} \Delta, 2 \mathrm{Dy}$ and $2 \mathrm{Ho}$ is enantiomeric pure with the Flack parameters close to zero (Table S1). However, the enantio pure isomers of the [ $\mathrm{Ln}(\mathrm{R}$ $\left.\left.\mathrm{C}_{2} \mathrm{~B}_{10} \mathrm{H}_{10}\right)_{2}\right]^{5-}$ complexes are randomly crystallized, and the whole batches of samples show nearly racemic property. To further analyze this phenomenon, we took $2 \mathrm{~Tb}$ as an example. We randomly selected ten crystals and solved the structures. Almost half of them give the left-handed $(\Lambda)$ enantiomer $(2 \mathrm{~Tb} \Lambda)$ and the other half gives the right-handed $(\Delta)$ enantiomer $(\mathbf{2 T b} \Delta)$. They are mirror-symmetry related structures (Figure S2). Similar results can be also found in other lanthanide analogues. ${ }^{[42]}$

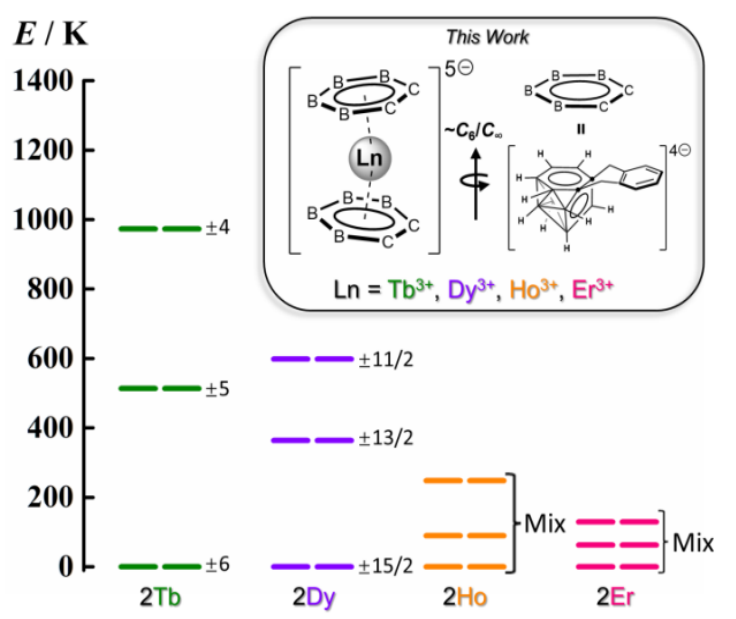

Figure 2 The $a b$ initio calculated electronic states. Comparison of $a b$ initio calculated electronic states of $\left[\mathrm{Ln}\left(\mathrm{R}-\mathrm{C}_{2} \mathrm{~B}_{10} \mathrm{H}_{10}\right)_{2}\right]^{5-}(\mathrm{Ln}=\mathrm{Tb}, \mathrm{Dy}, \mathrm{Ho}, \mathrm{Er})$.

To check the crystal field effect of such a hexagonal-prismatic geometry we performed ab initio calculations at SACASSCF/RASSI level[43] for 2Dy, 2Tb, 2Ho and 2Er (see Supporting Information for details). The electronic structure of 2Tb gives a high axiality of ground state $g_{z}$ of 17.94 with a tunnel splitting gap ( $\left.\Delta_{\text {tun }}\right)$ of $0.0005 \mathrm{~cm}^{-1}$ (Figure S52). The principal magnetic axis points exactly to the center of the $\left[\mathrm{C}_{2} \mathrm{~B}_{4}\right]$ hexagonal face (Figure S51). The first and second excited states lie at around $514 \mathrm{~K}$ and $974 \mathrm{~K}$ (Figure 2) with relatively pure $m_{J}$ $=\mid \pm 5>$ and $| \pm 4\rangle$, respectively. The wave functions of states higher than the fourth excited state are highly mixed. Considering large enough $\Delta$ tun value and much higher transition possibility at the second excited state, Orbach relaxation is supposed to pass through this state, making theoretical energy barrier around $514 \mathrm{~K}$, which is close to the experimental value. For 2Dy, its ground Kramer Doublet (KD) possesses high axiality, which is reflected in its $g$-tensor of $g_{\mathrm{x}}=g_{\mathrm{y}}=0, g_{\mathrm{z}}=19.86$ and wave function of $97.9 \% \mid \pm 15 / 2>$. The excited KDs contain relatively pure wave function until the fifth $K D$ and $g_{z}$ angle of the fifth excited $\mathrm{KD}$ arrives at $75.95^{\circ}$, hinting that Orbach relaxation goes through this KD and theoretical energy barrier is about
$1091 \mathrm{~K}$ (Figure S50 and Table S3). Furthermore, the transition probabilities between ground states for $\mathbf{2 D y}$ is determined to be $2.8 \times 10^{-8} \mu_{\mathrm{B}}^{2}$, which is far less than that of $2 \mathrm{~Tb}$ with $27 \mu \mathrm{B}^{2}$ (Table S7 and S8). Compared with 2Dy and 2Tb, the energy gaps between the ground and first excited states of $2 \mathrm{Ho}$ and $2 \mathrm{Er}$ are much smaller and mixed under this crystal field (Figure 2, Tables S5 and S6).

Accordingly, the experimental magnetism of $2 \mathrm{Ho}$ and $2 \mathrm{Er}$ shows almost absent ac signals under zero DC field (Figure S30). Thus, below we mainly focus on discussing the magnetic properties of $\mathbf{2} \mathbf{T b}$ and $2 \mathrm{Dy}$.

The temperature dependence of molar magnetic susceptibilities $\left(\chi_{\mathrm{m}}\right)$ were collected for complexes 2Tb and 2Dy in the temperature range 2 to $300 \mathrm{~K}$ under an applied field of 1000 Oe (Figures S14 and S15), which gives $\chi \mathrm{m} T$ products of 2Tb and 2Dy (in emu K mol${ }^{-1}$ ) to be 11.53 and 13.59 at $300 \mathrm{~K}$, respectively. These values are consistent with the expected values of $11.82 \mathrm{emu} \mathrm{K} / \mathrm{mol}$ for the free $\mathrm{Tb}^{3+}\left(4 \mathrm{f}^{8}\right)$ ion and 14.17 emu $\mathrm{K} \mathrm{mol}^{-1}$ for the free $\mathrm{Dy}^{3+}\left(4 \mathrm{f}^{9}\right)$ ion. The $\chi \mathrm{m} T$ curve keeps decreasing to about $8.6 \mathrm{emu} \mathrm{K} \mathrm{mol}^{-1}$ at $2 \mathrm{~K}_{\text {for }} \mathbf{2} \mathrm{Tb}$ (Figure S14); while for 2Dy, decreasing slowly down to $6 \mathrm{~K}$ followed by a sharp drop-off to $7.2 \mathrm{emu} \mathrm{K} \mathrm{mol}^{-1}$ at $2 \mathrm{~K}$ (Figure S15). The isothermal magnetization $(M)$ at $2 \mathrm{~K}$ show the maximum values of $4.8 \mu_{\mathrm{B}}$ and $5.3 \mu_{\mathrm{B}}$ at $5 \mathrm{~T}$ for $2 \mathrm{~Tb}$ and $2 \mathrm{Dy}$, respectively. Both $\chi_{\mathrm{m}} T(T)$ and $M(H)$ plots can be well fitted by using our crystal field parameters obtained via the ab initio calculations described above.

The strong temperature and frequency dependent ac susceptibilities under zero dc field of 2Tb and 2Dy were revealed by temperature- and frequency- dependence of the inphase (the real component, $\chi^{\prime}$ ) and the out-of-phase (the imaginary component, $\chi^{\prime \prime}$ ) ac susceptibilities (Figures S18-S29). For 2Tb, (Figure S19a), the $\chi^{\prime \prime}$ curves under zero dc field give the "tails" of ac susceptibilities which submerge at low frequencies, indicating strong QTM in the low temperature range. For 2Dy the $\chi^{\prime \prime}(v)$ peaks are clearly observed up to $40 \mathrm{~K}$ under zero dc field (Figure S21). The relaxation times $(\tau)$ are thus extracted by using the CC-FIT program with generalized Debye model (Figures S31-S36). ${ }^{[44]}$ As ac susceptibility measurements for our SQUID can only detect relaxation time between $0.001 \mathrm{~s}$ to 1 second, we performed dc relaxation measurements to obtain the lower temperature relaxation data. After magnetizing a sample at $5 \mathrm{~T}$ for $5 \mathrm{~min}$ and we then reduced the magnetic field to 2000 Oe and detecting the magnetic moments at periodic time intervals. The obtained magnetic relaxation data were fitted to an exponential function (Equation S1; for detail, see Supporting Information). All the relaxation time data can be plotted in Figure 3.

As shown in Figure 3, each plot obeys the Arrhenius law $\left(\tau^{-1}=\tau_{0}^{-1} e^{-U_{e f f} / T}\right)$ in the high temperature regime, indicative of Orbach process. However, further cooling results in different relaxation behavior for each compound. For the $\mathrm{Tb}$ analogues (2Tb and 2Tb@2Y), the plots become power-law ( $\left.C T^{n}\right)$ like temperature-dependent, which is the characteristic of a twophonon Raman process. For the Dy analogues (2Dy and 2Dy@2Y), the relaxation time is much flat below $20 \mathrm{~K}$, indicating a dominant QTM process. According to this difference, the plots of temperature-dependent relaxation times for the $\mathrm{Tb}$ analogues were fitted using Equation 1, while the same equation without the $C T^{n}$ term was applied for the Dy analogues. 


$$
\tau^{-1}=\tau_{0}^{-1} e^{-U_{e f f} / T}+C T^{n}+\tau^{-1}{ }_{Q T M} \quad \text { Eq. } 1
$$

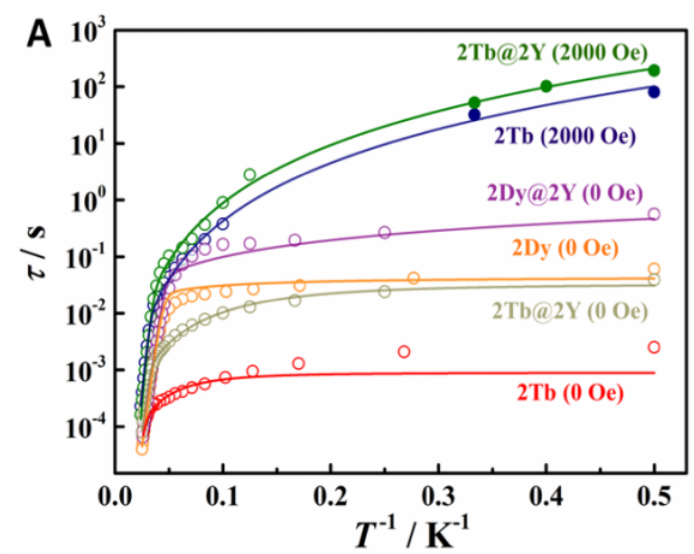

B

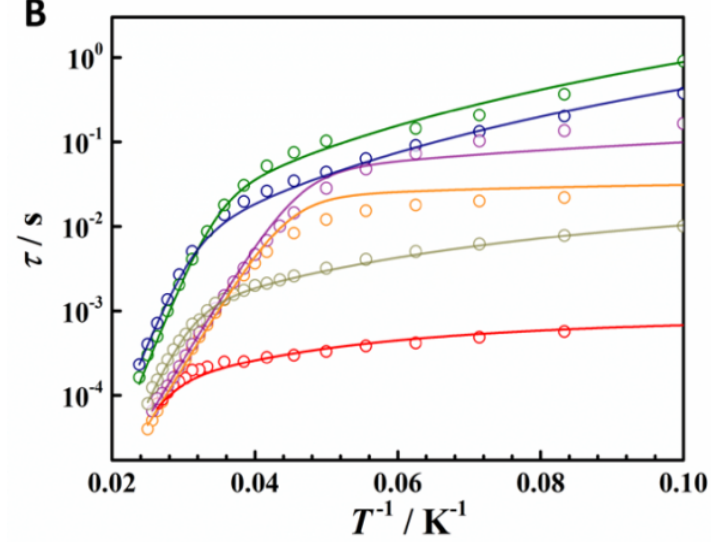

Figure 3 The temperature-dependent of the relaxation time. (A) The plots are for 2Dy (orange plot), 2Dy@2Y (purple plot), 2Tb (red plot) where $H_{\mathrm{dc}}=0 \mathrm{Oe}$, 2Tb where $H_{\mathrm{dc}}=2000$ Oe (navy plot), 2Tb@2Y where $H_{\mathrm{dc}}=0$ Oe (pale green plot) and 2Tb@2Y where $H_{\mathrm{dc}}=2000$ Oe (olive plot). The hollow points are from the A.C. susceptibility data and the solid points are from measurements of the D.C. magnetic relaxation time. The solid lines are the best fit with equation 1. (B) The expanded region from Figure $3 \mathrm{~A}$ from $10 \mathrm{~K}$ to $50 \mathrm{~K}$.

The best fitting parameters are given in Table 2, from which we can see under zero dc field the effective energy barrier for the $\mathrm{Tb}$ analogue is larger than the Dy analogue, which is well consistent with the energy gaps of the ground and the first excited spin states obtained from ab initio calculations (see above). However, at lower temperatures we see the longer relaxation times for the Dy analogue, which prompts us a much significant QTM effects for the Tb analogue. To vary this hypothesis, we performed field-dependent relaxation time measurements. After optimization we found 2000 Oe dc field is the best to mitigate the QTM effect for the Tb analogue (Figures S24 and S25). By applying this field the relaxation times for both 2Tb and 2Tb@2Y are much enhanced, giving $U_{\text {eff }}=485(13) \mathrm{K}$, $\tau_{0}=2.4(2) \times 10^{-9}, C=9.4(2) \times 10^{-4} \mathrm{~s}^{-1} \mathrm{~K}^{-n}, n=3.4(2)$ for $2 \mathrm{~Tb}$ and $U_{\text {eff }}=485(13) \mathrm{K}, \tau_{0}=1.35(5) \times 10^{-9}, C=4.5(2) \times 10^{-4} \mathrm{~s}^{-1} \mathrm{~K}^{-\mathrm{n}}, n=$ 3.4(2) for 2Tb@2Y. At 2K, the relaxations times for 2Tb@2Y and 2Tb are 193(17) and 81(7) seconds, respectively (Figures 3, S37-S41 and Table S2).

For $2 \mathrm{~Tb}$ the hysteresis loops remain opening up to $4 \mathrm{~K}$ with a sweep rate of $20 \mathrm{mT} / \mathrm{s}$. (Figures S46-S48). For $2 \mathrm{Dy}$, the $T_{\mathrm{B}}{ }^{\mathrm{H}}$ is approaching $6 \mathrm{~K}$ with a sweep rate of $0.15 \mathrm{mT} / \mathrm{s}$ (Figures S44 and S45).
Table 2. Fitting parameters for 2Tb, 2Tb@2Y, 2Dy and 2Dy@2Y.

\begin{tabular}{ccccccc}
\hline & \multicolumn{2}{c}{ 2Tb } & \multicolumn{2}{c}{ 2Tb@2Y } & 2Dy & 2Dy@2Y \\
\hline Field (Oe) & 0 & 2000 & 0 & 2000 & 0 & 0 \\
$U_{\text {eff }}[\mathrm{K}]$ & $445(10)$ & $485(13)$ & $445(10)$ & $485(13)$ & $320(10)$ & $320(10)$ \\
$\boldsymbol{\tau}_{\mathbf{0}}\left[10^{-10} \mathrm{~s}\right]$ & $13(3)$ & $24(2)$ & $13.9(2)$ & $13.5(5)$ & $150(3)$ & $180(3)$ \\
$C\left[\mathrm{~s}^{-1} \mathrm{~K}^{-\mathrm{n}}\right]$ & $2.3(3)$ & $9.4(2)$ & $0.42(3)$ & $4.5(2)$ & $/$ & $/$ \\
$n$ & $2.2(2)$ & $3.4(2)$ & $2.2(1)$ & $3.4(2)$ & $/$ & $/$ \\
$\boldsymbol{\tau}_{\text {QTM }}[\mathrm{s}]$ & $8.7(3)$ & $/$ & $0.033(2)$ & $/$ & $0.045(4)$ & $6.8(6)$ \\
\hline
\end{tabular}

It is worthy to compare with other high-performance $\mathrm{Tb}^{3+}$ based SMMs. The $U_{\text {eff }}$ of $445(10) \mathrm{K}$ for $2 \mathrm{~Tb}$ is higher than the five-member ringed $\left[\mathrm{Tb}\left(\mathrm{Cp}^{\mathrm{ttt}}\right)_{2}\right]^{+}$and the eight-member ringed $\left[\mathrm{Tb}\left(\mathrm{COT}^{\prime \prime}\right)_{2}\right]^{-}$(Figure 4). The outperformance for the sixmember ringed $\mathrm{Tb}$ sandwich than both five- and eight- member ringed analogues indicate other factors rather than the $\mathrm{Tb} \cdots$ centroid distance decides the relaxation parameters. This could be the symmetry since the $\mathrm{Tb}^{3+}$ ion lies in an approximately six-fold rotation axis and the local symmetry of the central $\mathrm{Tb}^{3+}$ ion is close to $D_{6 \mathrm{~h}}$. Similar situation was also found in $\left[\mathrm{TbFc}_{3} \mathrm{Li}_{2}(\mathrm{THF})_{2}\right]^{-}$and $\left[\mathrm{Tb}(\mathrm{Pc})_{2}\right]^{-}$, which have distorted trigonal-prismatic geometry with $D_{3 \mathrm{~h}}$ symmetry and squareantiprismatic geometry with $D_{4 \mathrm{~d}}$ symmetry, respectively. $\left[\mathrm{TbFc}_{3} \mathrm{Li}_{2}(\mathrm{THF})_{2}\right]^{-},\left[\mathrm{Tb}(\mathrm{Pc})_{2}\right]^{-}$and $\mathbf{2} \mathbf{T b}$ exhibit larger energy gaps between $m_{\lrcorner}= \pm 6$ and $m_{\lrcorner}= \pm 5$.If we further compare the energy barriers of their $\mathrm{Dy}^{3+}$ congeners we obtain the same order of magnitude. ${ }^{[45]}$ This is to tell us that the magnetic property of the central lanthanide ions brought by the arachno-carborane ligand is somehow similar to both ferrocenophane and phthalocyanine ligands. ${ }^{[23][26]}$

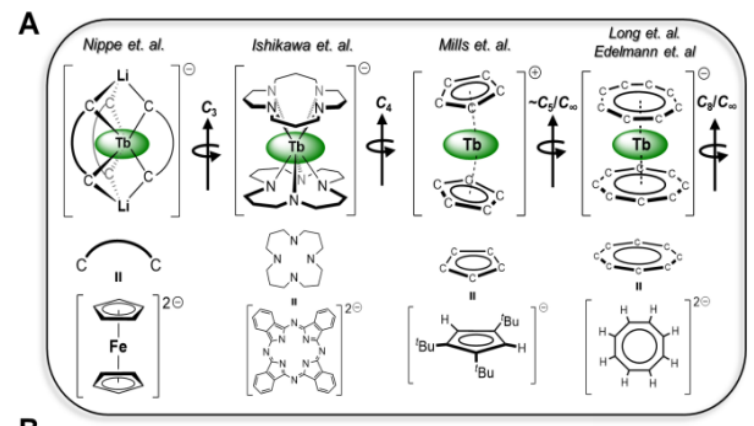

B

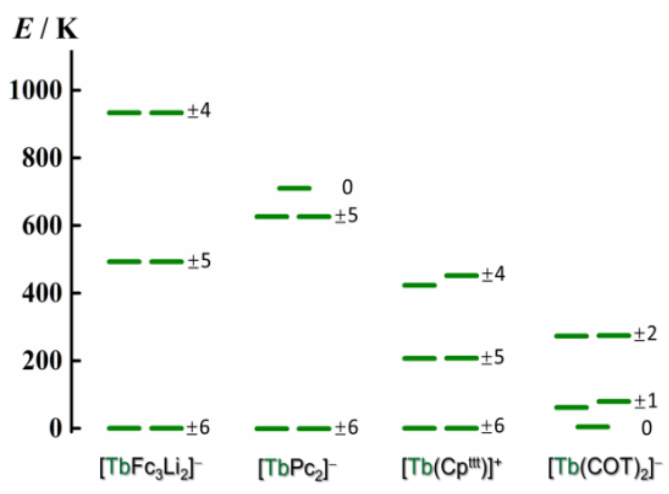

Figure 4 The structures and electronic states of other high performance $\mathrm{Tb}^{3+}$ based SMMs. (A) Comparison of structures of of $\left[\mathrm{TbFc}_{3} \mathrm{Li}_{2}\right]^{-},\left[\mathrm{Tb}(\mathrm{Pc})_{2}\right]^{-}$, $\left[\mathrm{Tb}\left(\mathrm{Cp}^{\mathrm{ttt}}\right)_{2}\right]^{+}$and $\left[\mathrm{Tb}(\mathrm{COT})_{2}\right]^{-}$, from left to right, respectively. (B) Comparison of ab initio calculated electronic states of $\left[\mathrm{TbFc}_{3} \mathrm{Li}_{2}\right]^{-},\left[\mathrm{Tb}(\mathrm{Pc})_{2}\right]^{-},\left[\mathrm{Tb}\left(\mathrm{Cp}^{\mathrm{ttt}}\right)_{2}\right]^{+}$and $\left[\mathrm{Tb}(\mathrm{COT})_{2}\right]^{-}$, from left to right, respectively 
In conclusion, the arachno- $\mathrm{R}_{2}-\mathrm{C}_{2} \mathrm{~B}_{10} \mathrm{H}_{10}{ }^{4-}$ carbollide is one of the few ligands that bears four negative charge and demonstrates aromaticity of the six-membered $\eta^{6}-\mathrm{C}_{2} \mathrm{~B}_{4}$ face for coordination. Theoretical study of this series of complexes including the $\mathrm{Tb}^{3+}, \mathrm{Dy}^{3+}, \mathrm{Ho}^{3+}$ and $\mathrm{Er}^{3+}$ analogues show the crystal field imparted by the local pseudo-twelve-coordinate hexagonal-prismatic geometry from the arachno- $\mathrm{R}_{2}-\mathrm{C}_{2} \mathrm{~B}_{10} \mathrm{H}_{10}{ }^{4-}$ ligand is similar to both ferrocenophane and phthalocyanine. All the fully sandwiched lanthanide complexes for these three different ligands give the same relation of $\mathrm{Tb}>\mathrm{Dy}>\mathrm{Ho}>\mathrm{Er}$ for the energy gaps between the ground and the first excited states despite that the local coordination geometries and symmetries are strikingly varied. The experimental investigation for the magnetic property of this family of arachno-lanthanacarborane complexes confirms this trend for $U_{\text {eff. }}$ Moreover, the observed $U_{\text {eff }}=445(10) \mathrm{K}, T_{\mathrm{B}}{ }^{\mathrm{H}}=4 \mathrm{~K}$ and the relaxation time of the yttrium diluted sample reaching 193(17) seconds under an optimized field at $2 \mathrm{~K}$ render $2 \mathrm{~Tb}$ as one of the best performed $\mathrm{Tb}^{3+} \mathrm{SMMs}$.

\section{Acknowledgements}

This work was supported by the Natural Science Foundation of China (no. 21971203), and Key Scientific and Technological Innovation Team of Shaanxi Province (2020TD-001). We also thank the Instrument Analysis Center of Xi'an Jiaotong University for the assistance in SC-XRD measurements from $\mathrm{Dr}$. Chang Huang.

Keywords: Terbium • carborane $\cdot$ magnetism $\bullet$ organometallics - hexagonal-prismatic

[1] R. Sessoli, D. Gatteschi, A. Caneschi, Nature 1993, 365, 141-143.

[2] (a) A. Zabala-Lekuona, J. M. Seco, E. Colacio, Coord. Chem. Rev. 2021, 441, 213984; (b) Y. Peng, A. K. Powell, Coord. Chem. Rev. 2021, 426, 213490; (c) J.-H. Wang, Z.-Y. Li, M. Yamashita, X.-H. Bu, Coord. Chem. Rev. 2021, 428, 213617.

[3] (a) C. A. P. Goodwin, Dalton Trans. 2020, 49, 14320-14337; (b) V. S Parmar, D. P. Mills, R. E. P. Winpenny, Chem. Eur. J. 2021, 27, 76257645.

[4] N. Ishikawa, M. Sugita, T. Ishikawa, S.-Y. Koshihara, Y. Kaizu, J. Am. Chem. Soc. 2003, 125, 8694-8695.

[5] S.-D. Jiang, B.-W. Wang, H.-L. Sun, Z.-M. Wang, S. Gao, J. Am. Chem. Soc. 2011, 133, 4730-4733.

[6] J. P. Durrant, B. M. Day, J. Tang, A. Mansikkamäki, R. A. Layfield, Angew. Chem. Int. Ed. 2022, DOI 10.1002/anie.202200525.

[7] (a) C. A. P. Goodwin, F. Ortu, D. Reta, N. F. Chilton, D. P. Mills, Nature 2017, 548, 439-442; (b) F.-S. Guo, B. M. Day, Y.-C. Chen, M.-L. Tong, A. Mansikkamäki, R. A. Layfield, Science 2018, 362, 1400-1403; (c) C. A. Gould, K. R. McClain, D. Reta, J. G. C. Kragskow, D. A. Marchiori, E. Lachman, E.-S. Choi, J. G. R. Analytis, D. Britt, N. F. Chilton, B. G. Harvey, J. R. Long, Science 2022, 375, 198-202.

[8] P. Zhang, F. Benner, N. F. Chilton, S. Demir, Chem 2021, DOI https://doi.org/10.1016/j.chempr.2021.11.007.

[9] K. R. McClain, C. A. Gould, K. Chakarawet, S. J. Teat, T. J. Groshens, J. R. Long, B. G. Harvey, Chem. Sci. 2018, 9, 8492-8503.

[10] C. A. Gould, K. R. McClain, J. M. Yu, T. J. Groshens, F. Furche, B. G. Harvey, J. R. Long, J. Am. Chem. Soc. 2019, 141, 12967-12973.

[11] P. Evans, D. Reta, G. F. S. Whitehead, N. F. Chilton, D. P. Mills, J. Am. Chem. Soc. 2019, 141, 19935-19940.

[12] (a) K. R. Meihaus, J. R. Long, J. Am. Chem. Soc. 2013, 135, 1795217957; (b) J. Moutet, J. Schleinitz, L. L. Droitte, M. Tricoire, F. Pointillart, F. Gendron, T. Simler, C. Clavaguéra, B. L. Guennic, O. Cador, G. Nocton, Angew. Chem. Int. Ed. 2021, 60, 6042-6046.
[13] L. Münzfeld, C. Schoo, S. Bestgen, E. Moreno-Pineda, R. Köppe, M. Ruben, P. W. Roesky, Nat. Commun. 2019, 10, 3135.

[14] P.-B. Jin, Y.-Q. Zhai, K.-X. Yu, R. E. P. Winpenny, Y.-Z. Zheng, Angew. Chem. Int. Ed. 2020, 59, 9350-9354.

[15] H. A. Kramers, Proc. Amsterdam Acad. 1930, 33, 959.

[16] Y -S. Ding, N. F. Chilton, R. E. P. Winpenny, Y.-Z. Zheng, Angew. Chem. Int. Ed. 2016, 55, 16071-16074.

[17] J. Liu, Y.-C. Chen, J.-L. Liu, V. Vieru, L. Ungur, J.-H. Jia, L. F. Chibotaru, Y.-H. Lan, W. Wernsdorfer, S. Gao, X.-M. Chen, M.-L. Tong, J. Am. Chem. Soc. 2016, 138, 5441-5450.

[18] Y.-C. Chen, J.-L. Liu, L. Ungur, J. Liu, Q.-W. Li, L.-F. Wang, Z.-P. Ni, L. F. Chibotaru, X.-M. Chen, M.-L. Tong, J. Am. Chem. Soc. 2016, 138, 2829-2837.

[19] J.-L. Liu, Y.-C. Chen, M.-L. Tong, Chem. Soc. Rev. 2018, 47, 24312453.

[20] Y.-S. Ding, K.-X. Yu, D. Reta, F. Ortu, R. E. P. Winpenny, Y.-Z. Zheng, N. F. Chilton, Nat. Commun. 2018, 9, 3134.

[21] Z.-H. Li, Y.-Q. Zhai, W.-P. Chen, Y.-S. Ding, Y.-Z. Zheng, Chem. Eur. J. 2019, 25, 16219-16224.

[22] X.-L. Ding, Y.-Q. Zhai, T. Han, W.-P. Chen, Y.-S. Ding, Y.-Z. Zheng, Chem. Eur. J. 2021, 27, 2623-2627.

[23] H. Wang, B. Wang, Y. Bian, S. Gao, J. Jiang, Coord. Chem. Rev. 2016, 306, 195-216.

[24] C. R. Ganivet, B. Ballesteros, G. de la Torre, J. M. Clemente-Juan, E. Coronado, T. Torres, Chem.-Eur. J. 2013, 19, 1457-1465.

[25] S. Demir, J. M. Zadrozny, J. R. Long, Chem. Eur. J. 2014, 20, 95249529.

[26] T. P. Latendresse, V. Vieru, B. O. Wilkins, N. S. Bhuvanesh, L. F Chibotaru, M. Nippe, Angew. Chem. Int. Ed. 2018, 57, 8164-8169.

[27] N. Zhou, Y. Ma, C. Wang, G. F. Xu, J. Tang, J. Xu, S. Yan, P. Cheng, L. Li, D. A. Liao, Dalton Trans. 2009, 8489-8492.

[28] X. Wang, L. Li, D. Liao, Inorg. Chem. 2010, 49, 4735-4737.

[29] E. Coronado, C. Gimenez-Saiz, A. Recuenco, A. Tarazon, F. M. Romero, A. Camon, F. Luis, Inorg. Chem. 2011, 50, 7370-7372.

[30] K. R. Meihaus, S. G. Minasian, W. W. Lukens, Jr., S. A. Kozimor, D. K. Shuh, T. Tyliszczak, J. R. Long, J. Am. Chem. Soc. 2014, 136, 60566068.

[31] J.-J. Wang, J. Sun, M. Yang, L.-C. Li, Inorg. Chem. 2015, 54, 1130711313.

[32] C.-X. Zhang, Z.-M. Qiao, Y.-K. Kong, B. Wang, Y.-Y. Zhang, Q.-L. Wang, J. Mol. Struct. 2015, 1081, 348-354.

[33] P. Hu, Z. Sun, X. Wang, L. Li, D. Liao, D. Luneau, New J. Chem. 2014, 38, 4716-4721.

[34] V. Lorenz, P. Liebing, M. Böhme, A. Buchholz, W. Plass, N. Geue, L. Hilfert, S. Busse, F. Engelhardt, C. G. Hrib, F. T. Edelmann, Eur. J. Inorg. Chem. 2017, 41, 4840-4849.

[35] C. A. P. Goodwin, D. Reta, F. Ortu, J. Liu, N. F. Chilton, D. P. Mills, Chem. Commun. 2018, 54, 9182-9185.

[36] J. G. Brennan, F. G. N. Cloke, A. A. Sameh, A. Zalkin, J. Chem. Soc Chem. Commun. 1987, 1668-1669.

[37] R. P. Kelly, L. Maron, R. Scopelliti, M. Mazzanti, Angew. Chem. Int. Ed. 2017, 56, 15663-15666.

[38] (a) G. Zi, H.-W. Li, Z. Xie, Organometallics 2001, 20, 3836-3838; (b) G Zi, H.-W. Li, Z. Xie, Organometallics 2002, 21, 3464-3470.

[39] E. B. Moore, L. L. Lohr, W. N. Lipscomb, J. Chem. Phys. 1961, 35, 1329.

[40] M. F. Hawthorne, D. C. Young, T. D. Andrews, V. D. Howe, R. L. Pilling, A. D. Pitts, M. Reintjes, L. F. Warren. Jr., P. A. Wegner, J. Am. Chem. Soc. 1968, 90, 879-896.

[41] T. Lu, F. Chen, J. Comput. Chem. 2012, 33, 580-592.

[42] K. Kumar, O. Stefanczyk, N. F. Chilton, K. Nakabayashi, K. Imoto, R. E. P. Winpenny, S. Ohkoshi, Inorg. Chem. 2021, 60, 12009-12019

[43] F. Ignacio, M. Galván, A. Ali, A. Celestino, A. Francesco, A. Jochen, J. B. Jie, I. B. Sergey, A. B. Nikolay, K. C. Rebecca, F. C. Liviu, et. al, Chem. Theory Comput. 2019, 15, 5925-5964.

[44] N. F. Chilton, CC-Fit, The University of Manchester, Manchester, UK, 2014, http://www.nfchilton.com/cc-fit.html

[45] T. P. Latendresse, N. S. Bhuvanesh, M. Nippe, J. Am. Chem. Soc. 2017, 139, 8058-8061. 


\section{Entry for the Table of Contents}

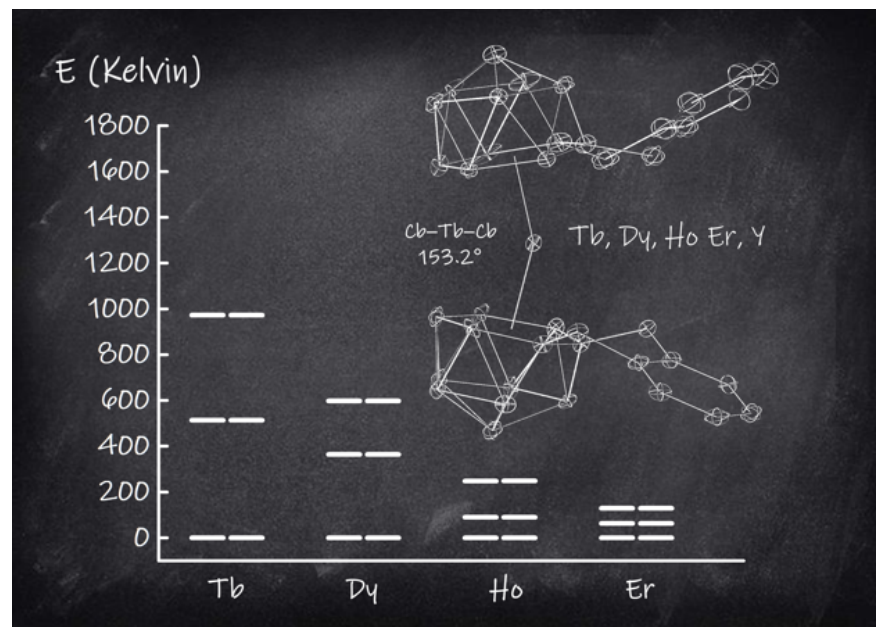

This work shows a family of fully sandwiched lanthanide complexes derived from the tetraanionic arachno-carboranyl ligand possess a novel hexagonal-prismatic local coordination geometry which significantly enhances the magnetic axiality of the Terbium(III) analogue. 